\title{
Endogenous glucose production, gluconeogenesis and liver glycogen concentration in obese non-diabetic patients
}

\author{
C. M üller ${ }^{1}$, F. A ssimacopoulos-J eannet' ${ }^{2}$, F. M osimann ${ }^{3}$, Ph. Schneiter ${ }^{1}$, J .P. R iou ${ }^{4}$, C. Pachiaudi ${ }^{4}$, J .P. Felber ${ }^{1}$, \\ E. J équier ${ }^{1}$, B. J eanrenaud ${ }^{5}$, L. Tappy ${ }^{1}$
}

${ }^{1}$ Institut de Physiologie, Université de Lausanne, Switzerland

${ }^{2}$ Département de Biochimie Médicale, Université de Genève, Switzerland

${ }^{3}$ Service de chirurgie générale CHUV, Lausanne, Switzerland

${ }^{4}$ INSERM U 449, Faculté de Médecine Laënnec, Lyon, France

${ }^{5}$ Laboratoire de Recherches Métaboliques, Université de Genève, Switzerland

Summary Resting, post-absorptive endogenous glucose production (EGP), fractional gluconeogenesis and liver glycogen concentration were assessed in 6 lean and 5 obese non-diabetic subjects undergoing elective abdominal surgery. During the 2 days preceding these measurements, $0.3 \mathrm{~g} /$ day $\mathrm{U}-{ }^{13} \mathrm{C}$ glucose had been added to their usual diet to label their endogenous glycogen stores. On the morning of day 3, EGP was measured with $6,6-{ }^{2} \mathrm{H}$ glucose. Their endogenous ${ }^{13} \mathrm{C}$ glycogen enrichment was calculated from ${ }^{13} \mathrm{CO}_{2}$ and respiratory gas exchanges. Fractional gluconeogenesis was assessed as $1-\left({ }^{13} \mathrm{C}\right.$ glucose $/{ }^{13} \mathrm{C}$ glycogen $) \cdot 100$. EGP was similar in lean subjects $(113 \pm 5 \mathrm{mg} / \mathrm{min})$ and in obese subjects $(111 \pm 6)$. Fractional gluconeogenesis was higher in obese $(59 \pm 10 \%)$ than in lean subjects $(29 \pm 8 \%)$.
However, overall EGP remained constant due to a decrease in glycogenolysis. Since an increased gluconeogenesis and a decreased glycogenolysis may both contribute to increase liver glycogen concentration in obesity, hepatic glycogen concentrations were assessed in hepatic needle biopsies obtained during surgery. Hepatic glycogen concentrations were increased in obese patients $(515 \pm 38 \mathrm{mg} / \mathrm{g}$ protein) compared to lean subjects $(308 \pm 58, p<0.05)$. It is concluded that in obese patients: a) fractional gluconeogenesis is increased; b) overall EGP is unchanged due to a proportional inhibition of glycogenolysis; c) liver glycogen concentration is increased. [Diabetologia (1997) 40: 463-468]

Keywords Substrate oxidation, glycogenolysis.
Non-insulin-dependent diabetes mellitus is characterized by an increased rate of endogenous glucose production (EGP) [1] which is essentially due to an increased gluconeogenesis $[2,3]$.

In healthy humans and animals, infusions of gluconeogenic precursors [4-8] stimulate gluconeogenesis from these substrates but do not increase EGP. Similarly, gluconeogenesis is increased during infusion of lipid emulsions which enhance plasma non-esterified fatty acid concentrations and whole body lipid oxidation rate, but EGP remains constant [9]. The

Received: 10 April 1996 and in final revised form: 31 December 1996

Corresponding author: Dr L. Tappy, Institut de Physiologie, 7 rue du Bugnon, CH-1005 Lausanne, Switzerland A bbreviations: EPG, Endogenous glucose production, APE, Atom percent excess. mechanisms responsible for this maintenance of a constant EGP when gluconeogenesis is stimulated have not been completely identified, but do not appear to involve alterations of plasma insulin, glucagon or glucose concentrations $[4,10]$. It has been suggested that suppression of glycogenolysis [4] or of gluconeogenesis from endogenous substrate [7] is involved. In addition, it has recently been observed that simultaneous glycogen synthesis and breakdown occur in hepatocytes [11], and that stimulation of glycogen synthesis occurs during infusion of gluconeogenic substrate $[10,12]$.

Obesity is characterized by an increased release of gluconeogenic precursors $[13,14]$, which may stimulate the gluconeogenic pathway. Splanchnic balance data indicated an increased uptake of gluconeogenic precursors in obese patients; such patients interestingly had total splanchnic glucose productions comparable to those observed in lean individuals [15]. 
Table 1. Physical characteristics of subjects and details of their surgical procedures

\begin{tabular}{|c|c|c|c|c|c|c|}
\hline Subjects & Age (years) & Male/female & Height $(\mathrm{cm})$ & Weight (kg) & $\begin{array}{l}\text { Body mass } \\
\text { index }\left(\mathrm{kg} / \mathrm{m}^{2}\right)\end{array}$ & $\begin{array}{l}\text { Surgical procedure } \\
\text { (clinical condition) }\end{array}$ \\
\hline \multicolumn{7}{|l|}{ Lean } \\
\hline 1 & 34 & Female & 152 & 45 & 20 & Gastrectomy (superficial carcinoma) \\
\hline 3 & 67 & Female & 155 & 60 & 25 & $\begin{array}{l}\text { Hemicolectomy (adenocarcinoma } \\
\text { of rectum) }\end{array}$ \\
\hline 6 & 57 & Female & 166 & 76 & 28 & Hemicolectomy (diverticulosis) \\
\hline Mean \pm SEM & $59 \pm 5$ & $3 / 3$ & $163 \pm 3$ & $66 \pm 5$ & $25 \pm 1$ & \\
\hline \multicolumn{7}{|l|}{ Obese } \\
\hline 1 & 47 & Female & 172 & 98 & 33 & Sigmoidectomy (polyposis) \\
\hline 2 & 69 & Male & 171 & 96 & 33 & Hemicolectomy (polyposis) \\
\hline$P$ value & NS & & NS & $<0.01$ & 0.01 & \\
\hline
\end{tabular}

The aim of the present study was to measure, in lean and obese non-diabetic subjects, total glucose production and the relative contributions of gluconeogenesis and glycogenolysis to EGP. Since changes of glycogen synthesis and breakdown are likely to be involved in the regulation of EGP, liver glycogen concentration was measured in needle liver biopsies obtained during surgery.

\section{Subjects and methods}

Subjects. Six lean and five obese patients undergoing elective abdominal surgery took part in this study. Their age, sex, and anthropometric characteristics are shown in Table 1 . The experimental protocol was approved by the Institutional Review Board for Human Investigation of Lausanne University School of Medicine, and all patients provided an informed written consent.

Study design. Two days before the study, breath and blood samples were collected for determination of the natural enrichment in ${ }^{13} \mathrm{C}$ of breath $\mathrm{CO}_{2}$ and plasma glucose. Subjects then ate their usual, unstandardized diet, but ingested $0.1 \mathrm{~g}$ uniformly labelled ${ }^{13} \mathrm{C}$ glucose (Isotec Inc, Miamisburg, Ohio, USA) mixed with a fruit juice with each of the three main meals. This procedure was aimed to label the endogenous glycogen stores with ${ }^{13} \mathrm{C}$.

On the evening preceding the experiment, the last meal was ingested before 18.00 hours; patients were thereafter admitted to the hospital, and an indwelling venous cannula was inserted into an antecubital vein of the forearm. Through the cannula a continuous infusion of $6,6-{ }^{2} \mathrm{H}$ glucose (Tracer Technologies, Sommerville, Mass., USA) was started at a rate of $60 \mu \mathrm{g}$. $\mathrm{kg}^{-1} \cdot \mathrm{min}^{-1} \cdot$ from 22.00 hours until the end of the experiment. At 06.30 hours the next morning, a second venous cannula was inserted in a hand vein of the controlateral arm for blood sampling at 07.00 and 07.30 hours. This hand was placed in a thermostabilized box heated to $56^{\circ} \mathrm{C}$ to achieve partial arterialization of venous blood. This allowed determination of the enrichments of plasma deuterated and ${ }^{13} \mathrm{C}$ labelled glucose, and plasma concentrations of glucose, insulin, non-esterified fatty acids and glucagon. Between 07.00 and 07.30 hours a ventilated canopy was fitted over the head and around the shoulders of the patients to monitor respiratory gas exchanges. Two breath samples were also collected for determination of the enrichment in ${ }^{13} \mathrm{C}$ of $\mathrm{CO}_{2}$ during this period. A urine collection was obtained between 22.00 and 07.00 hours for determination of urinary nitrogen excretion rate. Pre-operative medications (midazolam + morphine sulfate or atropine) were then administered, and patients were taken to the operating theatre 30 to 60 minutes after the end of these measurements. Anaesthesia was performed with the use of isoflurane, fentanyl and vecuronil bromide. Two needle biopsies of the right liver lobe were obtained at the beginning of the operation and were immediately stored in liquid nitrogen until further analysis.

Indirect calorimetry. Respiratory gas exchanges were monitored continuously by open circuit indirect calorimetry using a deltatrac (Datex II, Deltatrac Instruments, Helsinki, Finland). Energy expenditure, net glucose, fat and protein oxidation rates were calculated from respiratory gas exchanges and urinary nitrogen excretion [16].

I sotope analysis. Breath samples were collected in evacuated, air tight glass tubes (Europa Scientific Inc., Crewe, UK). Breath ${ }^{13} \mathrm{CO}_{2}$ isotope enrichment was determined by $\mathrm{CF}$ IRMS on a Roboprep G/Tracermass (Europa Scientific Inc.). Breath $\mathrm{CO}_{2}$ isotopic enrichment was calculated vs breath $\mathrm{CO}_{2}$ obtained prior to labelled glucose ingestion.

Plasma glucose isotope enrichments were determined on neutral fractions of deproteinized plasma samples partially purified over sequential anion-cation exchange resins. Plasma ${ }^{13} \mathrm{C}$ glucose enrichment was measured by gas chromatography-isotope ratio mass spectometry and was expressed in atom percent excess (APE) after derivatization to pentacetyl glucose [17]. Plasma $6,6-{ }^{2} \mathrm{H}$ glucose was measured by gas chromatographymass spectrometry of pentacetyl glucose, using the electron impact mode and selective monitoring of m/z 242.1 and 244.1.

Plasma hormone and substrate concentrations. Plasma glucose was determined by the glucose oxidase method using a 
Beckman Glucose Analyzer (Beckman Instruments, Fullerton, Calif., USA). Plasma insulin (kit from Biodata, Guidonia Montecellio, Italy) and glucagon (kit from DPC, Los Angeles, Calif., USA) were determined by radioimmunoassay. Urinary nitrogen was measured by the method of Kjehldahl [18]. Plasma non-esterified fatty acid concentration was determined colorimetrically using a kit from WAKO (Freiburg, Germany).

B iopsy analysis. Liver biopsies were assayed for glycogen content according to Chan and Exton [19]. Samples (10-15 mg) were homogenized in a buffer containing EDTA $10 \mathrm{mmol} / \mathrm{l}$, $\mathrm{KF} 50 \mathrm{mmol} / \mathrm{l}$, and glycerol $30 \%, \mathrm{pH} 7.0$, using a polytron. An aliquot of the homogenate was spotted on a ET31 Whatmann paper for glycogen determination. The protein concentration was determined on another aliquot [20].

Calculations. EGP, i.e. total rate of glucose appearance, was calculated from plasma $6,6-{ }^{2} \mathrm{H}$ glucose isotopic enrichment, using Steele's steady-state equation [21].

Fractional glycogenolysis and gluconeogenesis were calculated from breath ${ }^{13} \mathrm{CO}_{2}$, plasma ${ }^{13} \mathrm{C}$ glucose and respiratory gas exchanges. This calculation is based on the following assumptions. ${ }^{13} \mathrm{C}$ glucose administered with the diet on the 2 days preceding the measurements results in a substantial enrichment of endogenous glycogen while it does not affect enrichment of lipid or protein pools. As a result, in basal, post-absorptive conditions, oxidation of ${ }^{13} \mathrm{C}$ enriched, endogenous glycogen is the sole source of ${ }^{13} \mathrm{CO}_{2}$ enrichment. In addition, net carbohydrate oxidation corresponds essentially to oxidation by peripheral tissues of glucose issued from endogenous glycogen hydrolysis. Only liver glycogenolysis contributes to systemic glucose. In addition, it is assumed that oxidation of muscle glycogen represents only a minor portion of net carbohydrate oxidation in resting post-absorptive conditions. This assumption is based on the report that the respiratory exchange ratio of resting muscle is about 0.8 , and that skeletal muscle takes up a substantial amount of systemic glucose [22]. Calculation of the enrichment of endogenous glycogen in exercising healthy lean volunteers (i.e. a mixture of hepatic and skeletal muscle glycogen) has in addition been shown to be only $20 \%$ lower than the value calculated under resting conditions in the same subjects [23]. As a consequence, $\mathrm{CO}_{2}$ produced from the oxidation of glycogen-derived glucose has an enrichment in ${ }^{13} \mathrm{C}$ similar to that of hepatic glycogen. Labelled ${ }^{13} \mathrm{CO}_{2}$ is diluted with unlabelled $\mathrm{CO}_{2}$ produced from lipid and protein oxidation. Gluconeogenesis from glycerol or amino acids results in the production of unlabelled glucose with a natural, low ${ }^{13} \mathrm{C}$ abundance, the oxidation of which is included in net lipid and protein oxidations, respectively. This unlabelled neoformed glucose dilutes the labelled glucose originating from glycogen hydrolysis. ${ }^{13} \mathrm{C}$ glycogen enrichment and gluconeogenesis can then be calculated as described previously [24]:

${ }^{13} \mathrm{C}$ glycogen enrichment $(\mathrm{APE})=$
$\frac{\text { breath }{ }^{13} \mathrm{CO}_{2} \text { enrichment } \times \mathrm{VCO}_{2}}{\mathrm{VCO}_{2(\mathrm{CHO})} \times 0.8}$

where $\mathrm{VCO}_{2(\mathrm{CHO})}$ is the production of $\mathrm{CO}_{2}$ due to oxidation of carbohydrates, and 0.8 is the recovery factor of ${ }^{13} \mathrm{CO}_{2}$ in breath.

Fractional glycogenolysis $(\%)=$

$\frac{{ }^{13} \text { C glucose enrichment }}{{ }^{13} \mathrm{C} \text { glycogen enrichment }} \times 100$

Fractional gluconeogenesis $(\%)=100$-fractional glycogenolysis.
Table 2. Hormones and substrate concentrations

\begin{tabular}{lclll}
\hline Subjects & $\begin{array}{l}\text { Insulin } \\
(\mathrm{pmol} / \mathrm{l})\end{array}$ & $\begin{array}{l}\text { Glucagon } \\
(\mathrm{ng} / \mathrm{l})\end{array}$ & $\begin{array}{l}\text { Glucose } \\
(\mathrm{mmol} / \mathrm{l})\end{array}$ & $\begin{array}{l}\text { Non-esterified } \\
\text { fatty acids } \\
(\mathrm{mEq} / \mathrm{l})\end{array}$ \\
\hline Lean & $90 \pm 6$ & $61 \pm 9$ & $5.2 \pm 0.2$ & $0.68 \pm 0.11$ \\
Obese & $114 \pm 18$ & $77 \pm 1$ & $5.1 \pm 0.3$ & $0.64 \pm 0.04$ \\
\hline
\end{tabular}

Values are mean \pm SEM
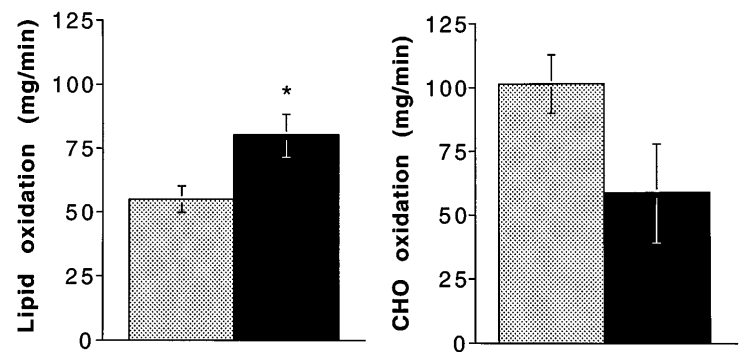

Fig. 1. Post-absorptive lipid and carbohydrate oxidation rates in lean $(\square)$ and obese $(\square)$ subjects. $* p<0.05$

Quantitative glycogenolysis or gluconeogenesis can then be obtained by multiplying fractional glycogenolysis or gluconeogenesis by EGP.

\section{Statistical analysis}

Results are expressed as mean \pm SEM. Data obtained in obese and lean patients were compared using the Wilcoxon rank sum test.

\section{Results}

H ormones and substrates. Plasma insulin and glucagon concentrations tended to be higher in obese patients compared to lean control patients whereas plasma glucose and non-esterified fatty acid concentrations were similar between the two groups of subjects (Table 2).

Substrate oxidation rates. Respiratory quotient was lower in obese $(0.78 \pm 0.02)$ than in lean patients $(0.84 \pm 0.01, p<0.05)$. Obese subjects had a decreased net carbohydrate oxidation $(59 \pm 19 \mathrm{mg} / \mathrm{min})$ and an increased lipid oxidation $(80 \pm 8 \mathrm{mg} / \mathrm{min})$ compared to lean subjects (carbohydrate oxidation: $101 \pm 11 \mathrm{mg} / \mathrm{min}$, lipid oxidation $55 \pm 5 \mathrm{mg} / \mathrm{min}$ ) (Fig.1). Protein oxidation rates $(25 \pm 7 \mathrm{mg} / \mathrm{min}$ in obese vs $20 \pm 2$ in lean subjects) and energy expenditure $(1.07 \pm 0.06 \mathrm{kcal} / \mathrm{min}$ in obese vs $0.97 \pm 0.02$ in lean subjects) were not significantly different between the two groups of subjects.

EGP, gluconeogenesis and glycogenolysis. EGP was similar in the two groups of subjects $(111 \pm 6 \mathrm{mg} / \mathrm{min}$ 
Table 3. ${ }^{13} \mathrm{C}$ isotopic enrichment in lean and obese patients

\begin{tabular}{llll}
\hline Subjects & $\begin{array}{l}{ }^{13} \mathrm{CO}_{2} \\
(\mathrm{APE})\end{array}$ & $\begin{array}{l}{ }^{13} \mathrm{C} \text { glucose } \\
(\mathrm{APE})\end{array}$ & $\begin{array}{l}{ }^{13} \mathrm{C} \text { glycogen } \\
(\mathrm{APE})\end{array}$ \\
\hline $\begin{array}{l}\text { Lean } \\
\text { Obese }\end{array} \mathrm{n}=6$ & $0.022 \pm 0.001$ & $0.042 \pm 0.003$ & $0.062 \pm 0.007$ \\
p value & $0.017 \pm 0.002$ & $0.034 \pm 0.003$ & $0.102 \pm 0.022$ \\
\hline
\end{tabular}

Values are mean \pm SEM

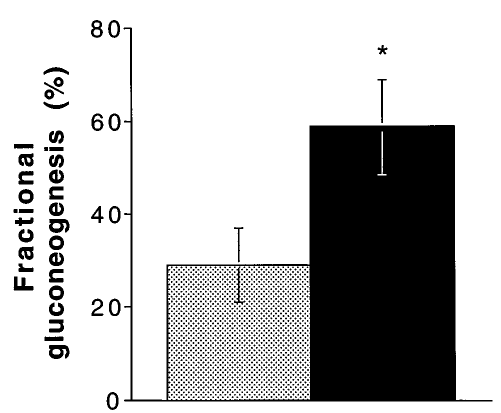

Fig. 2. Fractional gluconeogenesis in lean $(\square)$ and obese subjects. $* p<0.05$

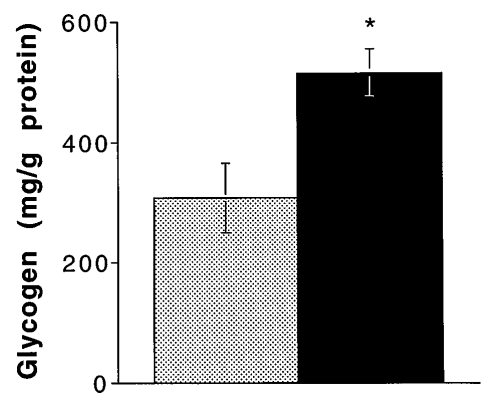

Fig. 3. Hepatic glycogen concentration in liver needle biopsies of lean $(\square)$ and obese $(\square)$ subjects. $* p<0.05$

in obese vs $113 \pm 5$ in lean subjects). Breath ${ }^{13} \mathrm{CO}_{2}$ and plasma ${ }^{13} \mathrm{C}$ glucose enrichments tended to be lower and hepatic ${ }^{13} \mathrm{C}$ glycogen enrichment to be higher in obese patients compared to lean control subjects as shown in Table 3.

Fractional gluconeogenesis was increased in obese patients $(59 \pm 10 \%)$ compared to lean subjects $(29 \pm 8 \%, p<0.05)$ (Fig. 2). Absolute rates of gluconeogenesis were increased in obese patients $(67 \pm 14 \mathrm{mg} / \mathrm{min}$ vs $34 \pm 10 \mathrm{mg} / \mathrm{min}$ in lean patients), although the difference did not reach significance $(p=0.10)$. Absolute rates of glycogenolysis were suppressed in obese patients $(44 \pm 11 \mathrm{mg} / \mathrm{min}) \mathrm{com}$ pared to lean control subjects $(79 \pm 6 \mathrm{mg} / \mathrm{min}$, $\mathrm{p}<0.05)$.

H epatic glycogen concentration. Analysis of liver biopsies revealed a significantly higher glycogen concentration in obese patients compared to lean control subjects $(515 \pm 38$ vs $308 \pm 58 \mathrm{mg} / \mathrm{g}$ protein respectively) (Fig. 3).

\section{Discussion}

The methodology used in the present study to assess fractional rates of glycogenolysis and gluconeogenesis differs markedly from the methods previously used to quantitate gluconeogenesis [25, 26]. It assesses the contribution of glycogenolysis to overall EGP from the measurement of plasma ${ }^{13} \mathrm{C}$ glucose, and an indirect assessment of liver ${ }^{13} \mathrm{C}$ glycogen enrichment. Gluconeogenesis is then calculated as the difference between EGP and glycogenolysis. In these experiments, the ${ }^{13} \mathrm{C}$ enrichment of hepatic glycogen extracted from liver biopsies was also measured (data not shown). This calculated value of liver ${ }^{13} \mathrm{C}$ glycogen enrichment was substantially higher than the measured enrichment of the glycogen extracted from liver biopsies $(0.020 \pm(\mathrm{SD}) 0.009 \mathrm{APE})$. This latter value was even lower than plasma ${ }^{13} \mathrm{C}$ glucose enrichment, which indicates that only a minor portion of hepatic glycogen was actually participating in glycogen turnover in these sedentary individuals. We postulate that only the peripheral portion of the glycogen molecules had incorporated labelled glycosyl unit, and that only this same portion of the molecule actively released glucose during the experiments. Using an identical protocol we have previously observed that the calculated ${ }^{13} \mathrm{C}$ glycogen enrichment remained constant in healthy individuals between hours 12 and 18 of a fast [27]. This observation corroborates that the portion of actively turning-over hepatic glycogen was homogeneously labelled. Although such data were not obtained in obese subjects, it appears very unlikely that inhomogeneous labelling of endogenous glycogen would have interfered with the present measurements performed over 30 to 60 min. periods.

This method provides estimates of the contribution of gluconeogenesis to endogenous glucose production which are somewhat higher than those previously reported using splanchnic catheterization or rate of labelled glucose synthesis during infusion of labelled gluconeogenic precursors in healthy subjects fasted overnight. Measures obtained using in vivo ${ }^{13} \mathrm{C}$ nuclear magnetic resonance spectroscopy [3] or ${ }^{2} \mathrm{H}$ glucose synthesis after ${ }^{2} \mathrm{H}_{2} \mathrm{O}$ administration [28] reported even higher rates of fractional gluconeogenesis [3].

There is, however, a limitation to the present method which has to be emphasized. In the Cori and glucose-alanine cycles, plasma glucose (a mixture of labelled glucose originating from glycogen hydrolysis and of unlabelled glucose originating from gluconeogenesis) is taken up by peripheral tissues to be partly released as lactate or alanine, which have essentially the same enrichment as plasma glucose. Although part of the tracer will be lost to $\mathrm{CO}_{2}$ when these counpounds undergo gluconeogenesis, this can be expected to affect only slightly overall plasma ${ }^{13} \mathrm{C}$ 
glucose enrichment. As a consequence, fractional gluconeogenesis will not account for the activity of these cycles. The amount of glucose produced from the cycling between plasma glucose and three carbon compounds has been reported to represent 3 to $30 \%$ of glucose turnover in healthy subjects and up to $45 \%$ in obese diabetic patients [29, 30]. In addition, it is possible that muscle glycogenolysis or adipose tissue lipolysis release labelled lactate and glycerol, which may also lead to an underestimation of gluconeogenesis with the present method. Compared to lean subjects, obese patients had a similar glucose production but a lower net carbohydrate oxidation, and therefore a higher non-oxidative glucose disposal. Since the cycling between plasma glucose and three carbon compounds is included in this non-oxidative glucose disposal, it is likely that gluconeogenesis was even somewhat more underestimated in obese patients than in lean subjects using this technique.

The major observation of this study is that obese non-diabetic patients have a twofold increase in fractional gluconeogenesis $(59 \pm 10 \%)$ compared to lean control subjects $(29 \pm 8 \%)$. The mechanisms responsible for this increased gluconeogenesis are not clearly established. A larger delivery of gluconeogenic substrates to the liver, a stimulation of gluconeogenic precursor uptake by liver cells, or an enhanced activity of gluconeogenic enzymes could all possibly be involved.

It has been reported that obese patients produce excessive amounts of gluconeogenic precursors. Glycerol production is increased in obesity [14]. Protein turnover rate and consequently free amino acid availability, is increased in obese patients [13]. Lactate has been also shown to be produced in excessive amounts by adipocytes of obese subjects [31].

Although gluconeogenesis was increased in obese non-diabetic patients, overall endogenous glucose production was comparable to that observed in lean subjects. This indicates that the regulation of EGP observed in healthy subjects is unaltered in obesity. There is evidence in healthy humans that basal hepatic glucose production remains constant when gluconeogenesis is acutely increased by infusion of gluconeogenic precursors $[4,7,10]$. An inhibition of glycogenolysis, an inhibition of gluconeogenesis from substrates other than the infused precursor and a stimulation of hepatic glycogen synthesis have all been suggested to participate in this acute regulation of EGP. The present results clearly indicate that in obese patients, an increased gluconeogenesis from endogenous glucose precursors is compensated for by a suppression of glycogenolysis in order to keep overall glucose output in the normal range. The mechanism which signals for inhibition of glycogenolysis cannot be determined from the present data. It may be hypothesized that the increased blood insulin concentration of obese patients contributes to the decreased glycogenolysis. Alternatively, an increase in gluconeogenesis may lead to an increase in intracellular glucose-6-phosphate and free glucose concentrations, which will favour deactivation of glycogen phosphorylase.

There was a $67 \%$ increase in average glycogen concentration in liver cells of obese patients compared to lean subjects. Some of the lean patients had localized cancer, but an extensive staging failed to detect any dissemination of the tumours; furthermore, no patient reported recent weight loss or signs of malnutrition. It is therefore unlikely that their condition was responsible for a decrease in hepatic glycogen. We also considered sex distribution in the two groups as a possible explanation for the observed difference in hepatic glycogen. It appears however unlikely, because hepatic glycogen content was higher in 3 lean males $(504 \mathrm{mg} / \mathrm{g}$ protein on average) than in $3 \mathrm{fe}-$ males $(280 \mathrm{mg} / \mathrm{g}$ protein on average). In contrast, we cannot discard the hypothesis that age difference may contribute to variations in hepatic glycogen content.

This increase in glycogen concentrations in the liver of obese patients may be secondary to the decreased glycogenolysis observed in these patients. Alternatively, it may be hypothesized that the increased glucose-6-phosphate produced by gluconeogenesis initially stimulated glycogen synthesis, as observed in healthy subjects when gluconeogenic precursors are acutely infused $[10,12]$. The increased glycogen concentration may secondarily inhibit glycogen synthesis, leading to further changes in the intracellular concentrations of intermediary substrates, which may be responsible for inhibition of glycogenolysis.

Three of the lean patients underwent surgery because of malignancies, and their clinical condition may have been a confounding factor. Cancer patients, however, have been shown to have enhanced, not decreased hepatic gluconeogenesis [32].

From these data, we conclude that obese non-diabetic patients have an increased fractional gluconeogenesis. Total hepatic glucose production, however, remains comparable to that observed in lean subjects due to a proportional reduction in glycogenolysis. The increased rate of gluconeogenesis and the suppression of glycogenolysis may both contribute to increase hepatic glycogen concentrations in these patients.

A cknowledgements. This work was supported by grants from the Swiss National Science Foundation (\# 32-37247.93), the Professor Dr Max Cloëtta Foundation as well as from the Raymond Berger Foundation. 


\section{References}

1. DeFronzo RA (1988) The triumvirate: $\beta$-cell, muscle, liver. A collusion responsible for NIDDM. Diabetes 37: 667-687

2. Consoli A, Nurjhan N, Capani F, Gerich J (1989) Predominant role of gluconeogenesis in increased hepatic glucose production in NIDDM. Diabetes 38: 550-575

3. Magnusson I, Rothman DL, Katz LD, Shulman RG, Shulman GI (1992) Increased rate of gluconeogenesis in type II diabetes mellitus. A ${ }^{13} \mathrm{C}$ nuclear magnetic resonance study. J Clin Invest 90: 1323-1327

4. Jenssen T, Nurjhan N, Consoli A, Gerich JE (1990) Failure of substrate-induced gluconeogenesis to increase overall glucose appearance in normal humans. J Clin Invest 86: 489-497

5. Winkler B, Rathgeb I, Bjerknes C, Steele R, Altszuler N (1973) Effect of norepinephrine on glycerol and glucose metabolism in the normal dog. Am J Physiol 225: 81-84

6. Winkler B, Rathgeb I, Steele R, Altszuler N (1970) Conversion of glycerol to glucose in the normal dog. Am J Physiol 219: 497-502

7. Jahoor F, Peters EJ, Wolfe RR (1990) The relationship between gluconeogenic substrate supply and glucose production in humans. Am J Physiol 258:E288-E296

8. Wolfe RR, Jahoor F, Shaw JHF (1987) Effect of alanine infusion on glucose and urea production in man. J Parenter Enter Nutr 11: 109-111

9. Clore JN, Glickman PS, Nestler JE, Blackard WG (1991) In vivo evidence for hepatic autoregulation during FFAstimulated gluconeogenesis in normal humans. Am J Physiol 261:E425-E429

10. Tounian P, Schneiter P, Henry S, Jéquier E, Tappy L (1994) Effects of infused fructose on endogenous glucose production, gluconeogenesis and glycogen metabolism in healthy humans. Am J Physiol 267:E710-E717

11. Magnusson I, Rothman DL, Jucker B, Cline GW, Shulman RG (1994) Liver glycogen turnover in fed and fasted humans. Am J Physiol 266:E796-E803

12. Tappy L, Cayeux M-C, Schneiter P et al. (1995) Effects of lactate on glucose metabolism in healthy subjects and in severely injured hyperglycemic patients. Am J Physiol 268:E630-E635

13. Welle S, Barnard RR, Statt M, Amatruda JM (1992) Increased protein turnover in obese women. Metabolism 41: 1028-1034

14. Jahoor F, Klein S, Wolfe R (1992) Mechanism of regulation of glucose production by lipolysis in humans. Am J Physiol 262:E353-E358

15. Felig P, Wahren J, Hendler R, Brundin T (1974) Splanchnic glucose and amino acid metabolism in obesity. $\mathrm{J}$ Clin Invest 53: 582-590

16. Elia M, Fuller N, Murgatroyd PR (1988) The potential use of the labelled bicarbonate method for estimating energy expenditure in man. Proc Nutr Soc 47: 247-258

17. Tissot S, Normand S, Guilluy R et al. (1990) Use of a new gas chromatograph isotope ratio mass spectrometer to trace exogenous ${ }^{13} \mathrm{C}$ labelled glucose at a very low level of enrichment in man. Diabetologia 33: 449-456

18. Hawk P (1947) The Kjeldahl method. In: Hawk PB, Oser BL, Simonson WH (eds) Practical physiological chemistry. Blakiston, Toronto, pp 814-822

19. Chan TM, Exton JH (1976) A rapid method for the determination of glycogen content and radioactivity in small quantities of tissues or isolated hepatocytes. Anal Biochem 71: 96-105

20. Bradford M (1976) A rapid and sensitive method for the quantitation of microgram quantities of protein utilizing the principle of protein-dye binding. Anal Biochem 72: 248-254

21. DeBodo R, Steele R, Altszuler N, Dunn A, Bishop J (1963) On the hormonal regulation of carbohydrate metabolism: studies with ${ }^{14} \mathrm{C}$-glucose. Recent Prog Horm Res 19: 445488

22. Kelley DE, Mokan M, Simoneau JA, Mandarino LJ (1993) Interaction between glucose and free fatty acid metabolism in human skeletal muscle. J Clin Invest 92: 91-98

23. Gay L-J, Schutz Y, DiVetta V, Schneiter P, Tappy L, Jéquier E (1994) Measurement of ${ }^{13} \mathrm{CO}_{2}$ in expired air as an index of compliance to a high carbohydrate diet naturally enriched in ${ }^{13} \mathrm{C}$. Int $\mathrm{J}$ Obes 18: 591-595

24. Gay LJ, Schneiter P, Schutz Y, Di Vetta V, Jéquier E, Tappy L (1994) A non invasive assessment of hepatic glycogen kinetics and post-absorptive gluconeogenesis in man. Diabetologia 37: 517-523

25. Felig P, Wahren J, Hendler R (1978) Influence of maturityonset diabetes on splanchnic glucose balance after oral glucose ingestion. Diabetes 27: 121-126

26. Chiasson JL, Liljenquist JE, Lacy WW, Jennings AS, Cherrington AD (1977) Gluconeogenesis: methodological approaches in vivo. Fed Proc 36: 229-235

27. Haesler E, Schneiter P, Temler E, Jéquier E, Tappy L (1995) Effects of lactate infusion on hepatic gluconeogenesis and glycogenolysis. Clin Physiol 15: 581-595

28. Landau BR, Wahren J, Chandramouli V, Schumann WC, Ekberg K, Kalhan SC (1996) Contributions of gluconeogenesis to glucose production in the fasted state. J Clin Invest 98: 378-385

29. Tserng K-Y, Kalhan SC (1983) Estimation of glucose carbon recycling and glucose turnover with $\left[\mathrm{U}_{-}{ }^{13} \mathrm{C}\right]$ glucose. Am J Physiol 245:E476-E482

30. Tappy L, Acheson K, Curchod B et al. (1994) Overnight glucose metabolism in obese non insulin dependent diabetic patients and in healthy lean individuals. Clin Physiol 14: 251-265

31. Jansson P-A, Larsson A, Smith U, Lönnroth P (1994) Lactate release from the subcutaneous tissue in lean and obese men. J Clin Invest 93: 240-246

32. Bozzetti F (1995) Nutrition support in patients with cancer. In: Payne-James J, Grimble G, Silk D (eds) Artificial nutrition support in clinical practice. Edward Arnold, London, pp 511-533 